\title{
Newborn Piglets with Meconium Aspiration Resuscitated with Room Air or 100\% Oxygen
}

\author{
PER ARNE TØLLØFSRUD, ANNE BEATE SOLÅS, AND OLA DIDRIK SAUGSTAD
}

Department of Pediatric Research [P.A.T., A.B.S., O.D.S.], Institute for Surgical Research [P.A.T., A.B.S.], Department of Pediatrics [P.A.T.], The National Hospital, Oslo, Norway

\begin{abstract}
We investigated whether newborn piglets exposed to hypoxemia and severe meconium aspiration could be reoxygenated with room air as efficiently as with $100 \% \mathrm{O}_{2}$. Twenty-one 2- to 5-d-old piglets were randomly divided into three groups: 1) the room air group: hypoxemia, meconium aspiration, and reoxygenation with room air $(n=8) ; 2)$ the $\mathrm{O}_{2}$ group: hypoxemia, meconium aspiration, and reoxygenation with $100 \% \mathrm{O}_{2}(n=8)$; and 3 ) the control group: meconium aspiration, and reoxygenation with room air $(n=5)$. Hypoxemia was induced by ventilation with $8 \% \mathrm{O}_{2}$ until the mean blood pressure reached $<20$ $\mathrm{mm} \mathrm{Hg}$ or the base excess reached $<-20 \mathrm{mM}$. At this point, reoxygenation was started with either room air or $100 \% \mathrm{O}_{2}$. Three milliliters per kilogram of meconium $110 \mathrm{mg} / \mathrm{mL}$ was instilled into the trachea immediately before the start of reoxygenation. The $\mathrm{O}_{2}$ tension in arterial blood was significantly lower in the room air group; at 5 min of reoxygenation it was $9.1 \pm 0.5$ $\mathrm{kPa}$ versus $43.5 \pm 6 \mathrm{kPa}$ in the $\mathrm{O}_{2}$ group $(p<0.05)$. At $5 \mathrm{~min}$
\end{abstract}

\section{ABSTRACT}

of reoxygenation the tidal volume per kilogram was $12.1 \pm 0.7$ $\mathrm{mL} / \mathrm{kg}$ in the room air group and $13.1 \pm 0.9 \mathrm{~mL} / \mathrm{kg}$ in the $\mathrm{O}_{2}$ group (NS). There were no significant differences between the room air and the $\mathrm{O}_{2}$ groups during $120 \mathrm{~min}$ of reoxygenation in mean arterial blood pressure, pulmonary arterial pressure, cardiac index, base excess, or plasma hypoxanthine. In conclusion, hypoxic newborn piglets with meconium aspiration were found to be reoxygenated as efficiently with room air as with $100 \% \mathrm{O}_{2}$. (Pediatr Res 50: 423-429, 2001)

BE, base excess

\section{Abbreviations}

MABP, mean arterial blood pressure

PAP, mean pulmonary artery blood pressure

PIP, peak inspiratory pressure

$\mathrm{PaCO}_{2}$, arterial $\mathrm{CO}_{2}$ tension

$\mathbf{P a O}_{2}$, arterial $\mathrm{O}_{2}$ tension
Meconium aspiration syndrome (MAS) continues to be one of the most common causes of neonatal respiratory distress. Recent reports (1) show that amniotic fluid is stained with meconium in approximately $12.5 \%$ of all deliveries. And MAS has been found to occur in one tenth of infants born with meconium-stained amniotic fluid, with a mortality of $4.9-37 \%$ (median 12\%) (1). It thus contributes significantly to the total number of deaths in neonatal intensive care units (2), and is the primary cause of transfer to extracorporeal membrane oxygenation $(1,3)$. In two recent studies from developing countries (4, 5) meconium-stained amniotic fluid was present in approximately $40 \%$ of cases where infants required resuscitation at birth, indicating that meconium aspiration (MA) perhaps represents an even larger problem in these parts of the world.

Hypoxia is known to cause meconium passage into the amniotic fluid through hormonal and neural influence on the bowl

Received February 10, 2000; accepted October 29, 2000.

Correspondence and reprint requests: Per Arne Tølløfsrud, Department of Pediatric Research, The National Hospital, NO-0027 Oslo, Norway; e-mail: p.a.tollofsrud@klinmed.uio.no

Supported, in part, by the Norwegian Foundation for Health and Rehabilitation, the Norwegian Council for Cardiovascular Disease, the Norwegian Women's Public Health Association, and the Research Council of Norway. peristalsis and defecation $(6,7)$. Hormonal and neural maturation in the intestine does not occur until about $38 \mathrm{wk}$ of gestation $(8$, 9), so that meconium staining of the amniotic fluid is rare before this gestational age. Meconium in amniotic fluid can lead to MA and MAS, which is clinically characterized by severe respiratory distress, right to left shunting of the blood, and hypoxemia. The pathophysiology of MAS is complex and involves airway obstruction, pulmonary inflammation, surfactant dysfunction, and imbalance in pulmonary vasoregulation (1). Asphyxia is an important contributory factor in this process (10).

Until recently, the use of $100 \% \mathrm{O}_{2}$ during resuscitation of asphyxiated newborn infants was commonly recommended (11). However, in the last few years, several animal studies $(12-15)$ and two clinical studies $(4,5)$ have shown that resuscitation with room air is as efficient as resuscitation with $100 \%$ oxygen, and the World Health Organization's new guidelines for resuscitation now recommend the use of room air for basic resuscitation of asphyxiated newborns without MA (16). We wished to test the hypothesis that room air is as efficient as $100 \% \mathrm{O}_{2}$ for reoxygenation even after MA, because the latter is the most important cause of lung problems during resuscitation of newborns. 


\section{METHODS}

To test our hypothesis, we performed a randomized controlled animal study with piglets exposed to hypoxemia and severe MA. The variables we measured were MABP, PAP, cardiac index (CI), BE, and plasma hypoxanthine.

Approval. The Norwegian Animal Experimental Board approved the experimental protocol. The animals were cared for and handled in accordance with the European Guidelines for the Use of Experimental Animals.

Surgical preparation. Twenty-six piglets, $2-5 \mathrm{~d}$ old, were delivered from a local farmer on the day of the experiment. Five piglets were excluded; two because of low $\mathrm{Hb}$ at baseline, one because of death from air embolus in the lungs/heart at baseline, and two because of death from hypoxia at the start of reoxygenation $\left(\mathrm{O}_{2}\right.$ group $)$.

General anesthesia was induced by halothane $3 \%$ reduced to $1-1.5 \%$ mixed with $100 \% \mathrm{O}_{2}$ and continued with pentobarbital sodium $20 \mathrm{mg} / \mathrm{kg}$ and pethidine $10 \mathrm{mg} / \mathrm{kg}$ i.v. as a bolus injection in an ear vein. A continuous pentobarbital infusion at a rate of $6 \mathrm{mg} / \mathrm{kg} / \mathrm{h}$ during surgery and $3 \mathrm{mg} / \mathrm{kg} / \mathrm{h}$ during hypoxemia and reoxygenation in the room air and $100 \% \mathrm{O}_{2}$ groups was administered in a femoral vein. The rate of infusion was reduced because pentobarbital amplifies the hypoxemiainduced fall in MABP. For the control piglets, $6 \mathrm{mg} / \mathrm{kg} / \mathrm{h}$ of pentobarbital was given throughout the experiment. At regular intervals during the experiment, we administrated a painful stimulus by pinching the snout, and if the piglets showed signs of pain, additional pethidine was given. A continuous infusion containing $0.7 \% \mathrm{NaCl}$ and $1.25 \%$ glucose was given at a rate of $10 \mathrm{~mL} / \mathrm{kg} / \mathrm{h}$ in the right femoral vein. Blood glucose was measured regularly with a Haemo-Glucotest (Roche Molecular Biochemicals, Mannheim, Germany) and the infusion was adjusted to maintain blood glucose between 4 and $10 \mathrm{mM}$. Lidocaine $1 \%$ was used as a local anesthetic.

The piglets were tracheotomized and a $3.5-\mathrm{mm}$ uncuffed Portex endotracheal tube (Portex Ltd Hythe, Kent, UK) was inserted, with a ligature around the tube and trachea to prevent leakage. They were then ventilated with a pressure-controlled ventilator, Dräger Babylog 8000+ (Drägerwerk, Lübeck, Germany). Normoventilation $\left(\mathrm{PaCO}_{2} 4.5-6 \mathrm{kPa}\right)$ and a tidal volume of $10-15 \mathrm{~mL} / \mathrm{kg}$ were achieved by adjusting the PIP or ventilation rate. During surgery, stabilization and hypoxia the ventilation rate was 30 breaths pr minute. An inspiratory time of $0.4 \mathrm{~s}$ and a positive end-expiratory pressure of $3 \mathrm{~cm} \mathrm{H}_{2} \mathrm{O}$ were kept constant throughout the experiment.

Both femoral arteries and the right femoral and right external jugular veins were cannulated with polyethylene catheters (Portex PE-50, inner diameter $0.58 \mathrm{~mm}$ (Portex Ltd Hythe, Kent, UK)). Through a left-sided thoracotomy, an 8-mm ultrasonic transit time flow probe (Cardio Med, Medi-Stim, Oslo, Norway) was placed around the common pulmonary artery proximal to the ductus arteriosus for continuous recording of cardiac output (CO). For measuring the PAP, a catheter 0.8 $\mathrm{mm}$ outside diameter (Vygon, Ecouen, France) was inserted into the common pulmonary artery proximal to the flow probe using a Seldinger technique involving the introduction of a $20-\mathrm{G}$ needle and a $0.5-\mathrm{mm}$ outside diameter guidewire. The correct position was verified by the typical pressure curve of the pulmonary artery. For measuring the pressure in the left atrium, a 5F catheter with an inflatable balloon (Baxter Healthcare, Irvine, CA) was inserted into the left atrium through a small incision, the balloon was inflated with $0.25 \mathrm{~mL}$ of air, and a suture was placed around the incision. The chest wall was closed in two layers. The catheters were regularly flushed with heparinized saline $(4 \mathrm{U} / \mathrm{mL})$. The catheters in the left femoral artery, the right external jugular vein, the common pulmonary artery, and the left atrium were connected to strain gauge transducers. MABP, PAP, central venous pressure, and left atrium pressure were recorded continuously by a Gould recorder TA 5000 (Gould, Cleveland, OH). The heart rate (HR) was monitored by skin electrodes. The right femoral artery catheter was used for blood sampling. Rectal temperature was maintained between 38 and $40^{\circ} \mathrm{C}$ with a heating blanket or a radiant heating lamp. Inspired fraction of $\mathrm{O}_{2}$ and end-tidal $\mathrm{CO}_{2}$ were continuously monitored (Datex Normocap Oxy, Datex, Helsinki, Finland).

Meconium preparation. Meconium was obtained from the first stool of more than 20 healthy term neonates of both sexes. It was pooled, diluted with distilled water, and rotavaporated dry, then diluted with sterile saline to a concentration of 110 $\mathrm{mg} / \mathrm{mL}$. To achieve a homogeneous mixture, it was blended with a blender, Bosch MSM 4001/01(Robert Bosch, Stuttgart, Germany). The meconium mixture was kept in aliquots of 10 $\mathrm{mL}$ at $-20^{\circ} \mathrm{C}$ and slowly warmed up to $38^{\circ} \mathrm{C}$ before administration.

Experimental protocol. After a 30-min recovery period from surgery and before the start of hypoxia, the piglets were assigned by simple randomization to three groups. The randomization was done by the same person. Group 1 (room air group) was subjected to hypoxemia, MA, and reoxygenation with room air for $120 \mathrm{~min}(n=8)$. Group $2\left(\mathrm{O}_{2}\right.$ group $)$ was subjected to hypoxemia, MA, and reoxygenation with $100 \%$ $\mathrm{O}_{2}$ for $30 \mathrm{~min}$, followed by room air for $90 \min (n=8)$. Group 3 (control) was subjected to MA without hypoxemia and reoxygenated with room air for $120 \mathrm{~min}(n=5)$.

Hypoxemia was achieved by ventilation with a gas mixture: $8 \% \mathrm{O}_{2}$ in $\mathrm{N}_{2}$ (AGA, Oslo, Norway) until MABP fell below 20 $\mathrm{mm} \mathrm{Hg}$ or BE was $<-20 \mathrm{mM}$. Immediately before the start of reoxygenation, the piglets in all three groups received a bolus of $3 \mathrm{~mL} / \mathrm{kg}$ of the $110 \mathrm{mg} / \mathrm{kg}$ meconium mixture via the endotracheal tube. During the first $30 \mathrm{~s}$ after meconium instillation they were ventilated with a Laerdal bag at a rate of 60 breaths per minute and a pressure that induced adequate chest expansion. The piglets were then put back on the ventilator with a PIP $5 \mathrm{~cm} \mathrm{H}_{2} \mathrm{O}$ higher than baseline and the ventilation rate was increased from 30 to 60 breaths per minute. This was done to maintain a constant tidal volume of $10-15 \mathrm{~mL} / \mathrm{kg}$. During the first 30 min of reoxygenation, the $\mathrm{PaCO}_{2}$ was kept between 4.5 and $6 \mathrm{kPa}$ simply by altering the respiratory frequency, with a constant PIP. In the following $90 \mathrm{~min}$, normoventilation was obtained primarily by reducing the respiratory frequency until a rate of 30 breaths per minute was reached. If the piglets were still hyperventilating, the PIP was reduced. 
At the end of the study all the animals were killed with a dose of $100 \mathrm{mg} / \mathrm{kg}$ pentobarbital i.v. and the upper and lower lobes from the right lung were removed for histologic examination. The tissue specimens were excised, fixed in formalin, and stained with the periodic acid-Schiff (PAS) stain. The histology was then examined by a pathologist blinded to the treatment of the animals.

Blood samples. Blood samples for blood gas analysis were drawn from the femoral artery $30 \mathrm{~min}$ before the start of hypoxemia, at the start of hypoxemia (baseline), every $10 \mathrm{~min}$ during hypoxemia, at the start of reoxygenation, and after 5 , $10,15,30,45,60,90$, and $120 \mathrm{~min}$ of reoxygenation. Temperature-corrected acid/base status was measured with a Blood Gas Analyzer 860 (Ciba Corning Diagnostics, Midfield, MA, U.S.A.). $\mathrm{Hb}$ was measured at baseline and at the end of reoxygenation with a CO-Oximeter 482 (Instrumentation Laboratory, Lexington, MA, U.S.A.). Hematocrit was measured at the same time points by an ordinary centrifuge technique (results not shown).

Blood for hypoxanthine analysis was collected into prechilled EDTA-coated tubes and centrifuged without delay for 6 $\min$ at $1600 \times g$ at $4^{\circ} \mathrm{C}$. Plasma was transferred to polypropylene tubes and frozen at $-20^{\circ} \mathrm{C}$ until analysis. A three-fold volume of $0.9 \%$ sodium chloride replaced the withdrawn blood. Hypoxanthine concentration in plasma was analyzed by HPLC as previously described (14).

Lung function data measurements and calculation. The Dräger Babylog $8000+$ measured pressure and flow. Mean airway pressure was measured at the Y-piece. The lung volume was calculated as a function of flow. The ventilator performed the calculations of dynamic compliance $\left(\mathrm{C}_{\mathrm{dyn}}\right)$ and resistance (R) of the respiratory system using the ventilation curve for pressure, flow, and volume and a linear regression method that measured 120 values per second (17). According to a study by Roske et al. (18), the accuracy of the volume measurements made by the Babylog 8000 was sufficient for the lung volumes used in our study. Lung function was recorded at baseline, every 10 min during hypoxemia, at the start of reoxygenation, and at 5, 10, 15, 30, 45, 60, 90, and 120 min of reoxygenation.

Hemodynamic data collection and analyses. MABP, $\mathrm{PAP}$, left atrium pressure, $\mathrm{CO}$, and $\mathrm{HR}$ were logged into a computer using a software system developed for the logging of data (Work Bench PC for Windows, Strawberry Tree, Sunnyvale, CA, U.S.A.), using a logging frequency of $0.5 \mathrm{~Hz}$. Before statistical evaluation, mean values for the logged and calculated variables for each animal were calculated in blocks of $10 \mathrm{~s}$ (mean of five samples) to represent each point in time.

Statistics. All values are given as mean \pm SD. All three groups were compared for differences at baseline using oneway ANOVA with Fisher's PLSD posthoc test. An unpaired $t$ test was used to compare the room air and $\mathrm{O}_{2}$ groups to investigate whether there were any differences between the groups before the start of reoxygenation. And a paired $t$ test was used to compare two time points in the same group. A repeated measure ANOVA was used to compare values for the room air and $100 \% \mathrm{O}_{2}$ groups during the reoxygenation period. Repeated measure ANOVA with weight as covariance and simple regression analyses were performed to correlate for the difference in the weight between the groups. Two-sided $p$ values $<0.05$ were considered significant. These analyses were done with the statistical computer programs: StatView 5.0, (Abacus Concepts, Berkeley, CA, U.S.A.) and Social Science, Windows Release 8.0 (SPSS, Chicago, IL, U.S.A.). A graphics program (Graphpad Prism, version 2.01, Graphpad Software, San Diego, CA, U.S.A.) was used to produce the graphs.

\section{RESULTS}

The mean body weight in the room air group, $2.5 \pm 0.15 \mathrm{~kg}$, was significantly higher $(p=0.03)$ than in either the $\mathrm{O}_{2}$ group, $2.0 \pm 0.14 \mathrm{~kg}$, or the control group, $2.0 \pm 0.14 \mathrm{~kg}(p=0.04)$. The mean age was $3.8 \pm 0.3 \mathrm{~d}$ in the room air group, $3.5 \pm$ $0.4 \mathrm{~d}$ in the $\mathrm{O}_{2}$ group, and $3.4 \pm 0.7 \mathrm{~d}$ in the control group (NS). The mean duration of hypoxemia in the room air group was $34 \pm 6$ min versus $46 \pm 14 \mathrm{~min}$ in the $\mathrm{O}_{2}$ group (NS). Nor were there any significant differences between the room air and $\mathrm{O}_{2}$ groups in $\mathrm{PaO}_{2}, \mathrm{BE}$, plasma hypoxanthine, MABP, PAP, CI, and pulmonary vascular index at baseline or at the start of reoxygenation (Figs. 1 and 2).

Blood samples. $\mathrm{PaO}_{2}$ levels (Fig. 1) decreased from baseline to $4.3 \pm 0.1$ and $4.8 \pm 0.3 \mathrm{kPa}$ at the end of hypoxemia in the room air and $\mathrm{O}_{2}$ groups, respectively. During reoxygenation, $\mathrm{PaO}_{2}$ increased to $9.0 \pm 0.5 \mathrm{kPa}$ in the room air group versus $43.5 \pm 6 \mathrm{kPa}(p<0.05)$ in the $\mathrm{O}_{2}$ group at $5 \mathrm{~min}$ of reoxygenation. This difference persisted during the $30 \mathrm{~min}$ of reoxygenation with $100 \% \mathrm{O}_{2}$. Excluding the period of hyperoxia, there were no statistically significant differences between the room air and $\mathrm{O}_{2}$ groups. In the control group $\mathrm{PaO}_{2}$ decreased from $12.8 \pm 0.7$ to $6.9 \pm 0.8 \mathrm{kPa}$ from MA to $5 \mathrm{~min}$ of reoxygenation $(p<0.05)$. This indicates that there was acute lung injury from the MA.

BE (Fig. 1) decreased to a nadir of $-19.7 \pm 1.9$ and -22.2 $\pm 0.7 \mathrm{mM}$ at $5 \mathrm{~min}$ of reoxygenation and increased to $-1.9 \pm$ 0.8 and $-5.5 \pm 1.3 \mathrm{mM}$ after $120 \mathrm{~min}$ of reoxygenation in the room air and $\mathrm{O}_{2}$ groups, respectively. There were no significant differences between the two groups either during hypoxemia or reoxygenation.

Plasma hypoxanthine (Fig. 1) increased significantly from baseline level to a maximum of $116 \pm 6$ and $103 \pm 13 \mu \mathrm{mol} / \mathrm{L}$ at the start of reoxygenation and returned to baseline at the end of reoxygenation in the room air and $\mathrm{O}_{2}$ groups, respectively. We did not find any statistically significant differences between the groups during the experiment.

Hemodynamics. During hypoxemia, MABP (Fig. 2A) decreased to $38 \pm 8$ and $29 \pm 3 \mathrm{~mm} \mathrm{Hg}$ in the room air and $\mathrm{O}_{2}$ groups, respectively, (NS) at the start of reoxygenation. MABP returned to baseline levels after $5 \mathrm{~min}$ of reoxygenation. There were no significant differences in MABP between the room air and the $\mathrm{O}_{2}$ groups during the reoxygenation period. In the control group, the MABP decreased significantly after instillation of meconium and returned to baseline after $15 \mathrm{~min}$ of reoxygenation.

PAP (Fig. $2 B$ ) increased during the first part of hypoxia and fell subsequently in both the room air and $\mathrm{O}_{2}$ groups. During reoxygenation, PAP once more increased in the two groups but there were no statistically significant differences between the 

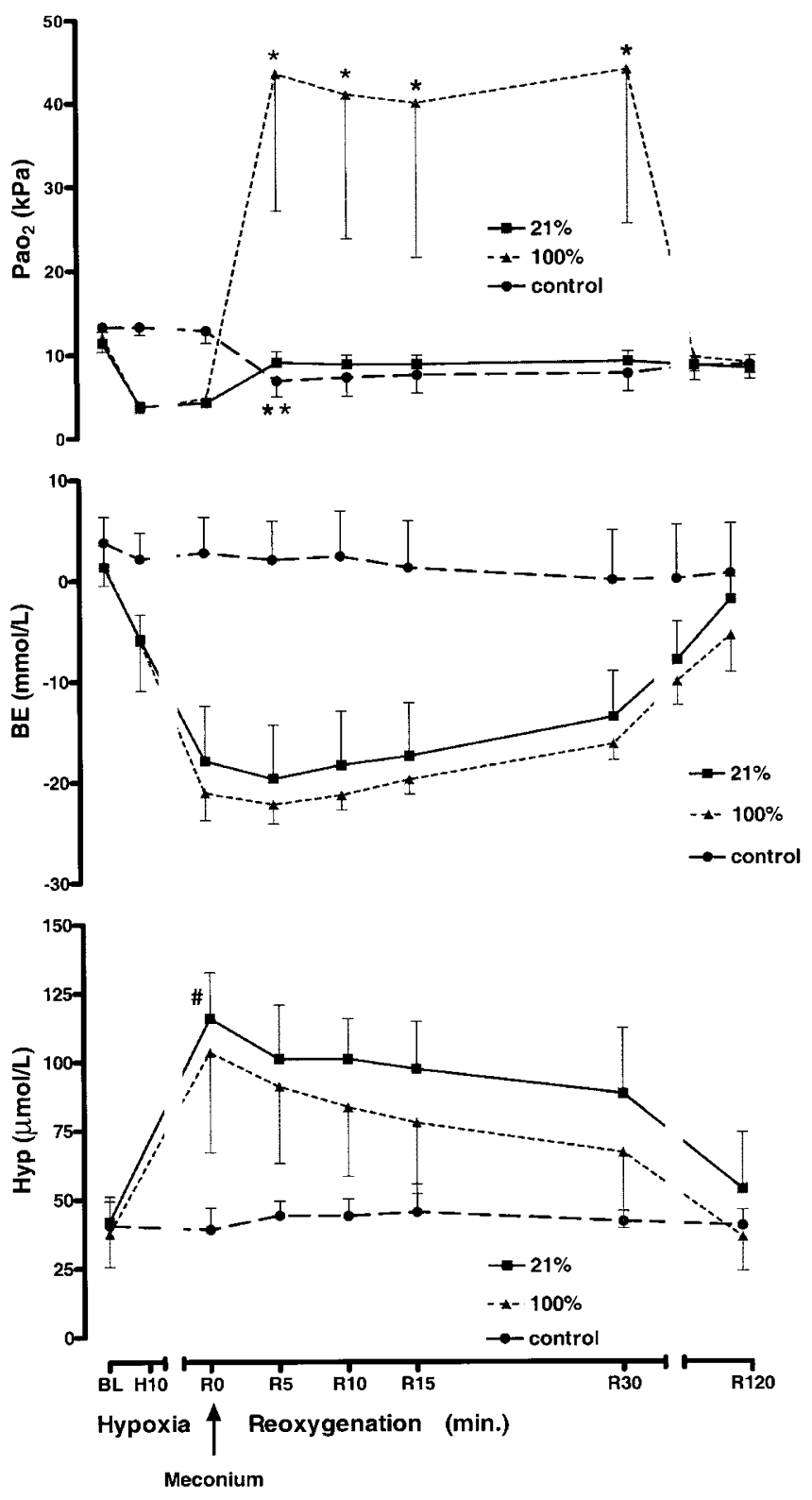

Figure 1. $\mathrm{PaO}_{2}, \mathrm{BE}$, and plasma hypoxanthine $(H y p)$ at baseline $(B L)$ and during hypoxia $(H)$ and reoxygenation $(R)$. Values are expressed as mean \pm SD. ${ }^{*} p<0.05$ room air $v s 100 \% \mathrm{O}_{2}$ group. ${ }^{* *} p<0.05$ start of reoxygenation vs 5 min of reoxygenation in the control group. $\# p<0.05$ baseline $v s$ start of reoxygenation in room air and $\mathrm{O}_{2}$ groups.

groups at any time. In the control group, PAP increased significantly after instillation of meconium.

The pulmonary vascular index (Fig. 2C) increased significantly during hypoxemia, but not during reoxygenation, without any differences between the room air and $\mathrm{O}_{2}$ groups.

The CI (Fig. 2D) decreased significantly in both the room air and $\mathrm{O}_{2}$ groups during hypoxemia, increased significantly to a maximum at $5 \mathrm{~min}$ of reoxygenation and then decreased to baseline levels. No significant differences were found between the room air and $\mathrm{O}_{2}$ groups at any time.

Lung functions. There were no significant differences in tidal volume per kilogram, PIP, or ventilation rate between the room air, $\mathrm{O}_{2}$, and control groups at any time (Table 1).
$\mathrm{C}_{\mathrm{dyn}}$ per kilogram (Table 1) was significantly different at baseline between the room air and $\mathrm{O}_{2}$ groups, with no differences at the start of reoxygenation or during reoxygenation. From baseline to 5 min of reoxygenation, $\mathrm{C}_{\mathrm{dyn}}$ per kilogram decreased significantly in all groups. After 5 min of reoxygenation $\mathrm{C}_{\mathrm{dyn}}$ per kilogram increased in all groups, but without completely reaching baseline level.

$\mathrm{R}$ (Table 1) increased significantly from baseline to the end of reoxygenation in the room air and $\mathrm{O}_{2}$ groups. In the control group, airway resistance increased significantly from the start of reoxygenation to end of reoxygenation. There were no significant differences between the room air and $\mathrm{O}_{2}$ groups from baseline to the end of reoxygenation.

Lung histology. In all the animals, widespread meconium was seen in peripheral airspace, with no differences between the groups.

\section{DISCUSSION}

These results demonstrate that newborn piglets exposed to hypoxemia followed by MA can be reoxygenated as efficiently with room air as with $100 \% \mathrm{O}_{2}$, assessed in terms of mean arterial blood pressure, PAP, CI, base deficit, and plasma hypoxanthine.

Unfortunately, there was a statistically significant difference in weight between the room air and $\mathrm{O}_{2}$ groups. To test the influence on the results, we performed statistical tests with weight as a covariant and regression analyses, and found that the weight difference had no influence. The $\mathrm{CO}$, tidal volume, and $\mathrm{C}_{\mathrm{dyn}}$ are also corrected for the weight. All medication and the amount of meconium instilled were given according to weight. Theoretically, one would expect that higher body weight in one group would increase the hypoxia time in this group, but this was not the case. The difference in weight was not large enough to make the surgical procedures more difficult in the groups with the smallest piglets. The degree of maturity of the piglets is probably more important than the body weight, but there were no differences in age between the groups.

Several investigators have studied MA in pigs, but hypoxemia was not induced before instillation of meconium in any of these studies (19-22). Meconium inhaled below the vocal cords in an unasphyxiated infant produces only mild benign self-limiting respiratory challenge that is asymptomatic in $>90 \%$ of cases (23-25). The animals in this experiment were hypoxemic but not hypercarbic. Hypoxia leads to vasoconstriction in the pulmonary circulation. Repeated or longstanding prelabor asphyxia is known to induce pulmonary arterial muscle hypertrophy and increased vascular hyperreactivity of the pulmonary vessels. Hypoxemia-induced pulmonary hypertension is an important change in pulmonary circulation in MAS. MA can occur either in utero, after hypoxia-induced gasping, or with the infant's first breath. In the present study, the hypoxemia before meconium instillation mimicked the clinical situation of aspiration of meconium in an infant exposed to a single period of hypoxemia followed by aspiration of meconium at the first breath.

However, in contrast to newborn infants, the piglets were $2-5 \mathrm{~d}$ old and, therefore, to some extent adapted to extrauterine 

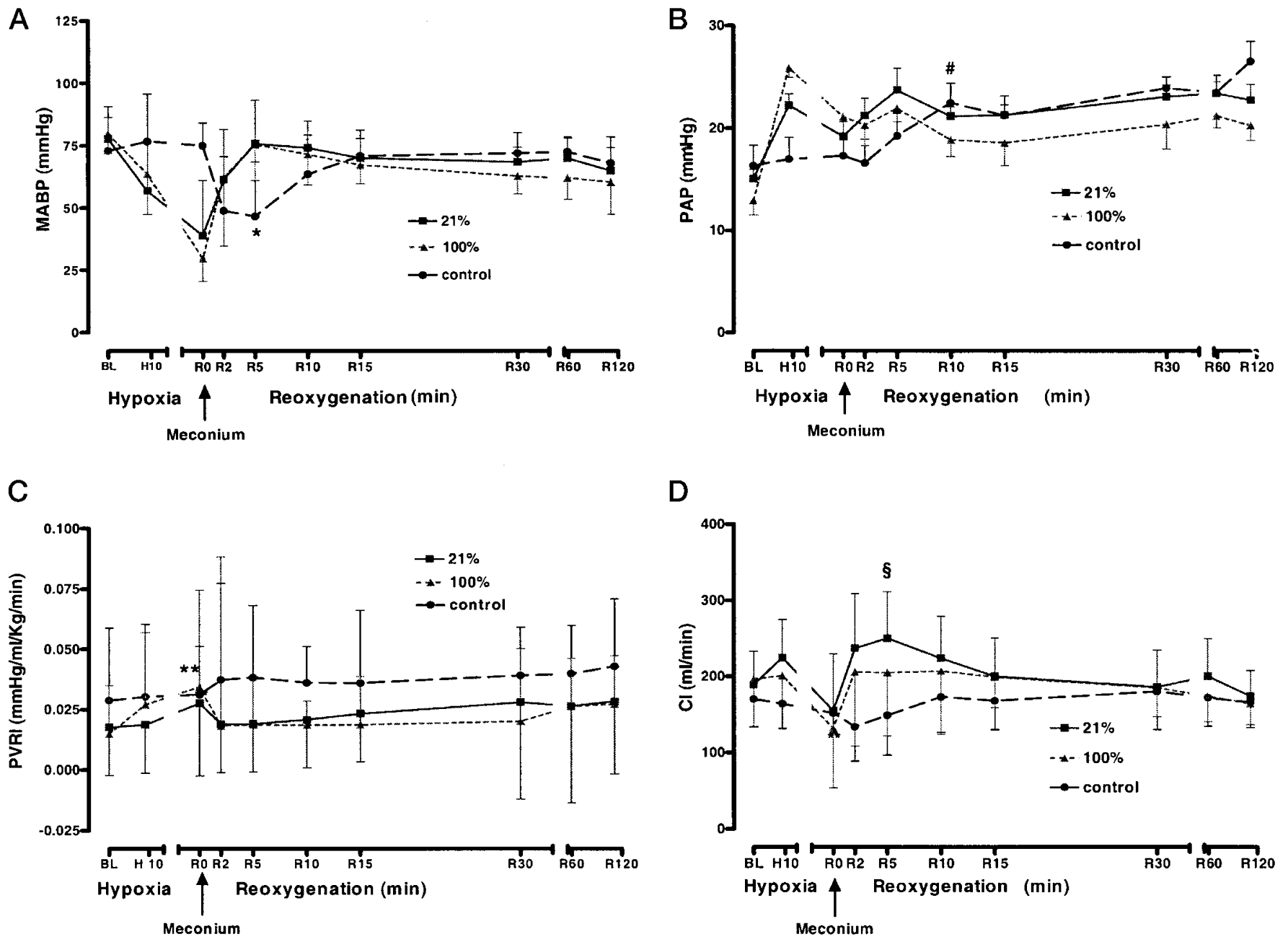

Figure 2. (A) MABP, $(B) \mathrm{PAP},(C)$ pulmonary vascular resistance index $(P V R I)$, and $(D)$ cardiac index $(C I)$, at baseline $(B L)$, during hypoxia $(H)$, and reoxygenation $(R)$. Values are expressed as mean $\pm \mathrm{SD}$. ${ }^{*} p<0.05$ start of reoxygenation $v s 5$ min of reoxygenation in the control group. $\# p<0.05$ start of reoxygenation $v s 10 \mathrm{~min}$ of reoxygenation in the control group. ${ }^{* *} p<0.05$ baseline $v s$ start of reoxygenation in the room air and $\mathrm{O}_{2}$ groups. $\$ p<0.05$ start of reoxygenation $v s$ min of reoxygenation in the room air and $\mathrm{O}_{2}$ groups.

life. In a clinical situation, this adaptation has barely started at the time of MA. Haworth et al. (26) studied the adaptation of the pulmonary circulation to extrauterine life in piglets and concluded that functionally the pulmonary circulation did not appear to be mature until the age of 2 wk and that an adult pattern was established by the age of 6 mo. These findings seem to justify our use of piglets that were a few days old, and to indicate that our results are applicable to the study of changes in the pulmonary pressure after hypoxemia and MA in newborns. However, in an unadapted lung, the migration time of meconium from the large to the smaller airways with aspiration is probably shorter because the amniotic fluid in the airways dilutes the meconium.

The use of anesthetics in experimental animal research will obviously affect the results and complicate interpretation and comparison with a clinical situation. We chose an anesthetic that would minimize distress for the piglets and at the same time have the least possible influence on the results. Strøm et al. (27) found that pentobarbital had no significant influence on hemodynamic performance over a wide range of plasma pentobarbital concentrations. Sensitivity to barbiturates and the influence on hemodynamics are altered by conditions such as hypoxemia (28). To compensate for this, we reduced the infusion of pentobarbital during hypoxemia. Pentobarbital has little analgesic effect, and must be supplemented by an opioid. To have as little effect as possible on hemodynamics, pethidine was only given if the piglets reacted to an additional painful stimulus.

MAS has a complex pathophysiology and has early and late effects (2). The early effects may be caused by the particulate nature of meconium and are primarily the result of obstruction leading to increased expiratory resistance, inactivation of surfactant, decreased dynamic lung compliance, hypoxemia, hypercapnia, and acidosis. The late effects are caused by the components of meconium and include inflammatory changes with airway and alveolar collapse secondary to chemical pneumonitis. In our study, we followed the piglets for $2 \mathrm{~h}$, so that the results only provide information on the early phase after MA.

Ninety five percent of cases of MAS develop in the presence of thick meconium. In the presence of thin meconium, the associated respiratory disease is mild (10). We therefore used 
Table 1. Lung function values

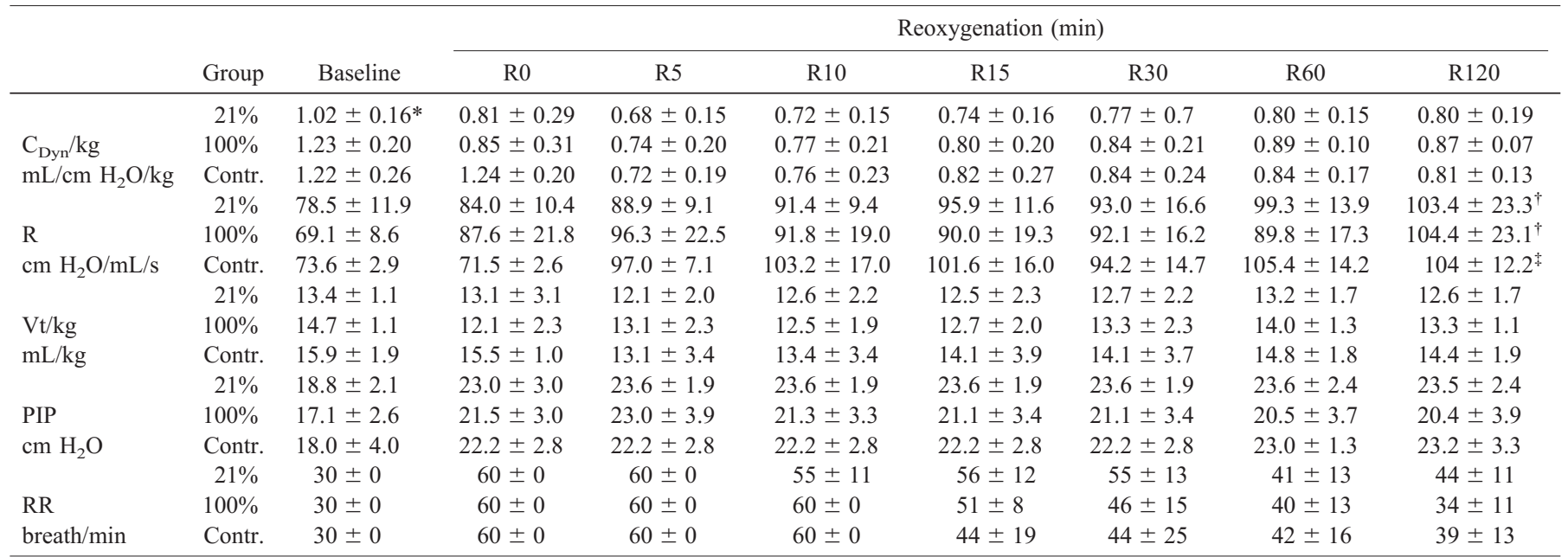

Values for dynamic compliance of the respiratory system $\left(\mathrm{C}_{\mathrm{Dyn}}\right)$, resistance of the respiratory system $(\mathrm{R})$, tidal volume per kilogram $(\mathrm{Vt} / \mathrm{kg})$, peak inspiratory pressure (PIP) and respiration rate (RR) in room air (21\%), oxygen (100\%) and control groups (Cont.). Values are expressed as mean \pm SD.

$* p<0.0521 \%$ group $v s 100 \%$ group at baseline.

$\dagger p<0.05$ baseline $v s$ end of reoxygenation in the room air and oxygen groups.

$\ddagger p<0.05$ start of reoxygenation $v s$ end of reoxygenation in the control group.

thick meconium, at a concentration of $110 \mathrm{mg} / \mathrm{mL}$, which had been homogenized with a blender. Others (20-22) have used filtered meconium. Airway obstruction is one of the early mechanical effects of MA (1), and we thought this effect might be reduced if the meconium were filtered. The findings in the control group clearly demonstrated that the meconium we used induced changes in the airways and the lungs compatible with those seen in human infants with MA.

At reoxygenation, $\mathrm{PaO}_{2}$ quickly normalized in the room air group, but reached supranormal values in the $100 \% \mathrm{O}_{2}$ group. Potentially toxic amounts of free oxygen radicals like superoxide radicals and highly reactive hydroxyl radicals may be produced during reoxygenation of hypoxic ischemic tissue. The production of radicals after severe hypoxia-ischemia may be proportional to tissue $\mathrm{Po}_{2}$ (29). High $\mathrm{Po}_{2}$ achieved during reactive hyperemia and high fractions of $\mathrm{O}_{2}$ during early resuscitation may therefore contribute to a burst of free oxygen radicals, resulting in damage to the epithelia and impairment of both production and functions of the surfactant system (30).

A key question is whether room air will reoxygenate the tissues as thoroughly as $100 \% \mathrm{O}_{2}$. During hypoxia, MABP falls, partly as a result of reduced myocardial contractility, resulting in a fall in cardiac output. In our study, MABP and CI increased as much in the room air as in the $\mathrm{O}_{2}$ group, indicating that the myocardium was oxygenated sufficiently during reoxygenation. Further, the fact that there were no significant differences between the groups in plasma hypoxanthine and $\mathrm{BE}$ during reoxygenation indicates that most tissues are reoxygenated as thoroughly with room air as with pure oxygen.

Although the complete mechanism of pulmonary vasorelaxation is not known, increasing $\mathrm{PaO}_{2}$, expansion and inflation of the lungs at birth are important factors (10). In our study, the piglets were exposed to only one period of severe hypoxemia during which PAP increased as expected, confirming that the pulmonary vessels were able to react. The control group showed a significant increase in PAP after instillation of meconium, indicating, as reported by others (20), that meconium alone induces pulmonary hypertension through an inflammatory process. There were no differences in PAP between the room air and $100 \% \mathrm{O}_{2}$ groups during reoxygenation, showing that resuscitation with room air provided sufficient $\mathrm{PaO}_{2}$ to dilate the pulmonary vascular system as efficiently as $100 \% \mathrm{O}_{2}$. If $\mathrm{O}_{2}$ is to be diffused from the lungs into the blood, the pressure of the inspired gas needs to be adequate and a sufficient volume of gas needs to be administered for the lungs to expand. Successful room air resuscitation depends upon adequate ventilation. In our study, both groups were equally ventilated, and there was no statistical differences between the groups in ventilation rate, PIP or $\mathrm{Vt} / \mathrm{kg}$.

We did not evaluate possible differences in hypoxicischemic brain damage. Although vital organs like the heart are as efficiently reoxygenated with room air as with $100 \% \mathrm{O}_{2}$, possible differences in hypoxic-ischemic brain damage should be ruled out before a clinical trial. There may be circumstances where resuscitation with $100 \% \mathrm{O}_{2}$ is superior to room air because the available alveolar surface is so reduced that room air is not sufficient to satisfactorily oxygenate the blood perfusing the lungs.

In conclusion, these results indicate that room air under certain circumstances may be good enough to resuscitate neonatal infants after meconium aspiration. More studies are needed in animal models before clinical trials can be considered.

Acknowledgment. We thank Thore Egeland for valuable advice on statistics.

\section{REFERENCES}

1. Cleary GM, Wiswell TE 1998 Meconium-stained amniotic fluid and the meconium aspiration syndrome. An update. Pediatr Clin North Am 45:511-529

2. Coltart TM, Byrne DL, Bates SA 1989 Meconium aspiration syndrome: a 6-year retrospective study. Br J Obstet Gynaecol 96:411-414 
3. Moront MG, Katz NM, Keszler M, Visner MS, Hoy GR, O'Connell JJ, Cox C, Wallace RB 1989 Extracorporeal membrane oxygenation for neonatal respiratory failure. A report of 50 cases. J Thorac Cardiovasc Surg 97:706-714

4. Ramji S, Ahuja S, Thirupuram S, Rootwelt T, Rooth G, Saugstad OD 1993 Resuscitation of asphyxic newborn infants with room air or $100 \%$ oxygen. Pediatr Res 34:809-812

5. Saugstad OD, Rootwelt T, Aalen O 1998 Resuscitation of asphyxiated newborn infants with room air or oxygen: an international controlled trial: the Resair 2 study. Pediatrics 102:e1

6. Dawes GS, Fox HE, Leduc BM, Liggins GC, Richards RT 1972 Respiratory movements and rapid eye movement sleep in the foetal lamb. J Physiol (Lond) 220:119-143

7. Duenhoelter JH, Pritchard JA 1977 Fetal respiration. A review. Am J Obstet Gynecol 129:326-338

8. Grand RJ, Watkins JB, Torti FM 1976 Development of the human gastrointestinal tract. A review. Gastroenterology 70:790-810

9. Lucas A, Adrian TE, Christofides N, Bloom SR, Aynsley-Green A 1980 Plasma motilin, gastrin, and enteroglucagon and feeding in the human newborn. Arch Dis Child 55:673-677

10. Katz VL, Bowes Jr WA 1992 Meconium aspiration syndrome: reflections on a murky subject. Am J Obstet Gynecol 166:171-183

11. American Heart Association 1992 Emergency Cardiac Care Committee and Subcommittees Guidelines for cardiopulmonary resuscitation and emergency cardiac care. VII. Neonatal resuscitation. JAMA 268:2276-2281

12. Rootwelt T, Loberg EM, Moen A, Oyasaeter S, Saugstad OD 1992 Hypoxemia and reoxygenation with $21 \%$ or $100 \%$ oxygen in newborn pigs: changes in blood pressure, base deficit, and hypoxanthine and brain morphology. Pediatr Res 32:107-113

13. Rootwelt T, Odden JP, Hall C, Ganes T, Saugstad OD 1993 Cerebral blood flow and evoked potentials during reoxygenation with 21 or $100 \% \mathrm{O}_{2}$ in newborn pigs. J Appl Physiol 75:2054-2060

14. Feet BA, Yu XQ, Rootwelt T, Oyasaeter S, Saugstad OD 1997 Effects of hypoxemia and reoxygenation with $21 \%$ or $100 \%$ oxygen in newborn piglets: extracellular hypoxanthine in cerebral cortex and femoral muscle. Crit Care Med 25:1384-1391

15. Medbo S, Yu XQ, Asberg A, Saugstad OD 1998 Pulmonary hemodynamics and plasma endothelin-1 during hypoxemia and reoxygenation with room air or $100 \%$ oxygen in a piglet model. Pediatr Res 44:843-849

16. World Health Organization Maternal and Newborn Health/Safe Motherhood Unit. Division of Reproductive Health (Technical Support). 1998 Basic Newborn Resuscitation: A Practical Guide. World Health Organization, Geneva
17. Drager Medizintechnik GmbH 1998 Babylog 8000 Plus Intensive Care Ventilators for Neonates: Instruction for Use. Version 5.n. Drager Medizintechnik GmbH, Lübeck, Germany, pp 125-126

18. Roske K, Foitzik B, Wauer RR, Schmalisch G 1998 Accuracy of volume measurements in mechanically ventilated newborns: a comparative study of commercial devices. J Clin Monit Comput 14:413-420

19. Davey AM, Becker JD, Davis JM 1993 Meconium aspiration syndrome: physiological and inflammatory changes in a newborn piglet model. Pediatr Pulmonol 16:101108

20. Soukka H, Halkola L, Aho H, Rautanen M, Kero P, Kaapa P 1997 Methylprednisolone attenuates the pulmonary hypertensive response in porcine meconium aspiration. Pediatr Res 42:145-150

21. Sun B, Curstedt T, Robertson B 1993 Surfactant inhibition in experimental meconium aspiration. Acta Paediatr 82:182-189

22. Sun B, Curstedt T, Robertson B 1996 Exogenous surfactant improves ventilation efficiency and alveolar expansion in rats with meconium aspiration. Am J Respir Crit Care Med 154:764-770

23. Rossi EM, Philipson EH, Williams TG, Kalhan SC 1989 Meconium aspiration syndrome: intrapartum and neonatal attributes. Am J Obstet Gynecol 161:11061110

24. Falciglia HS 1988 Failure to prevent meconium aspiration syndrome. Obstet Gynecol 71:349-353

25. Dooley SL, Pesavento DJ, Depp R, Socol ML, Tamura RK, Wiringa KS 1985 Meconium below the vocal cords at delivery: correlation with intrapartum events. Am J Obstet Gynecol 153:767-770

26. Haworth SG, Hislop AA 1981 Adaptation of the pulmonary circulation to extrauterine life in the pig and its relevance to the human infant. Cardiovasc Res 15:108-119

27. Strom J, Haggmark S, Reiz S, Sorensen MB 1987 Cardiovascular effects of pentobarbital in pigs, and the lack of response to naloxone in pentobarbital induced circulatory failure. Acta Anaesthesiol Scand 31:413-416

28. Gilman GA 1996 The Pharmacological Basis of Therapeutics, 9th Ed, McGraw-Hill, New York, pp 321-323

29. Fisher PW, Huang YC, Kennedy TP, Piantadosi CA $1993 \mathrm{PO}_{2}$-dependent hydroxyl radical production during ischemia-reperfusion lung injury. Am J Physiol 265:L279L285

30. Pitkanen OM HM 1998 Evidence for increased oxidative stress in preterm infants eventually developing lung disease. Semin Natol 3:199-205 